\title{
Development of Patient-Inclusive Teams: Toward a Structured Methodology
}

\section{L'accueil du patient dans l'équipe clinique : vers une méthodologie structurée}

Marie-Pascale Pomey, Paule Lebel, Nathalie Clavel, Édith Morin, Mireille Morin, Catherine Neault, Benoît Tétreault and Anna-Paulina Ewalds Mulliez

\section{Abstract}

Over the last few years, the role of patients in the health system has become essential to improving the quality of care and services. However, the literature shows that patient engagement is not always ideally applied to improve the quality and safety of care and that patient engagement can be tokenistic. Through experiences conducted in Quebec, it is possible to outline a structured process involving both professional stakeholders and patients that illustrates optimal conditions to be applied for successful teamwork involving patients.

\section{Résumé}

Au cours des dernières années, le rôle des patients dans le système de santé est devenu essentiel pour améliorer la qualité des soins et des services. Cependant, la littérature montre que l'engagement des patients n'est pas toujours réalisé idéalement pour améliorer la qualité et la sécurité des soins et que l'engagement des patients peut être symbolique. Au travers de l'expérience menée au Québec, il est possible de faire ressortir un processus structuré portant à la fois sur les intervenants et les patients, qui permet de mettre en œuvre les conditions optimales à une réussite du travail d'équipe incluant des patients. 


\section{KEY MESSAGES}

1. The success of teams that include patients rests upon a structured process applied not only to patients but also to professionals, to identify patient partners who wish to get involved and stakeholders motivated to transform their practices.

2. This structured process involves raising awareness at all levels of a health institution, selection and training of all team members, co-leader facilitation by a patient-professional duo, stakeholder coaching and mentoring and, finally, recognition of the work achieved by the team.

3. An evaluation of the contribution of the professionals and the patients must be systematically carried out to continuously improve the different approaches throughout the process, allowing teams to work in a harmonious way.

\section{Introduction}

Over the last few years, the role of patients in the healthcare system has become essential to improving the quality of care and services (Armstrong et al. 2013; Baker et al. 2016; Coulter 2012; Coulter and Ellins 2007; Grande et al. 2014; Groene et al. 2014; IHI 2014; Pomey and Lebel 2016; Richards et al. 2013). Indeed, only patients and their families know what it means to live with illness on a daily basis (Jouet et al. 2012; Pomey et al. 2015b), and they possess an integrated view of the organization of care and services within any care setting (Batalden et al. 2016; Cunningham and Walton 2016). In fact, Accreditation Canada revised all of its accreditation standards in 2016 to introduce, on the one hand, the need for care and services to be delivered in partnership with patients and their families and, on the other hand, the need for standards to be evaluated not only by health professionals and managers but also by patients and their families (Accreditation Canada 2015). However, the literature shows that patient engagement is not always ideally applied to improve the quality and safety of care. A recent literature review found that methods to engage patients at the clinical, organizational or political level of the healthcare system are not always optimal (Bombard et al. 2018) and that the patient's engagement can be tokenistic (Tritter and McCallum 2006). Indeed, patients sometimes report not making real contributions to decision-making because their input is not taken into account or because decisions are made before their participation (Todd et al. 2000). Also, beyond evaluating the openness of care teams and managers to work with patients, how can organizations ensure that these teams and individuals are well prepared to engage with them? This additional step of preparing teams for engagement is needed to affirm the pertinence of patients' and families' added value to care teams in different healthcare settings and at different levels of governance (AHRQ 2013).

In this article, using examples from the patient partnership movement emerging in Quebec, we present best practices to prepare teams to better engage with patient partners and families and show how teams appreciate patients' and families' engagement. In Quebec, the Ministry of Health and Social Services (MSSS) has incorporated patient partnership into its strategic orientations (MSSS 2015) and developed a framework for this approach (MSSS 2018), and the development of the Centre of Excellence on Partnership with Patients and the
Public (CEPPP) at the University of Montreal is helping to bolster the science of partnership and facilitate the integration of patient partnership into training, research and the healthcare system (CEPPP 2018). Different modalities and levels of patient engagement show how teams can be active in different settings (e.g., institutions of healthcare, primary care) and at different healthcare system levels (political, organizational and clinical).

In Quebec, the Montreal model (Pomey et al. 2015a) is one of patient partnership in healthcare and social services that is based on three main principles: (1) the recognition that patients and their families have experiential knowledge of a health situation and the use of services; (2) the acknowledgement of the status of patients/family members as full members of the (care) team; and (3) the recognition of their ability to make free and clear decisions based on their life goals.

\section{The Approaches and Levels of Engagement of Patients in Teams}

From the work of Carman et al. (2013) and Pomey et al. (2015a), it is possible to identify different contexts and situations that can lead teams to work with patients either at the clinical, organizational or political level.

\section{Approaches of engagement}

Knowing that patient engagement can take place on a continuum from information to co-construction (Carman et al. 2013; Pomey et al. 2015a), we focus here on how to prepare teams for collaboration and co-construction in partnership. By collaboration, we mean that patients are present to share their needs so that their perspective is taken into consideration. At the partnership level, engagement goes one step further to where involvement of patients leads to the co-construction of interventions or solutions.

\section{Levels of engagement}

At the clinical level, coherent with the principles of the Montreal model of partnership in care mentioned above (Pomey et al. 2015a), it is desirable to integrate patients and their families when developing their own interdisciplinary intervention plans. When patients require the coordination of several professionals for their health problems, it is important to create a specific moment(s) during which they can discuss 
with their care team members their priority needs, life goals and previous experiences with the disease and its treatments. Through these exchanges, patients, helped by health professionals, can make the best decisions to meet their own health expectations, and, concurrently, their healthcare professionals will understand why their patients prefer certain aspects of treatment when compared to others.

Another example of the integration of patients at the clinical level is the integration of peer patients into the care team as a service offered complementary to that of other health professionals. Accompanying (peer) patients are individuals who have had significant experience with a health condition and are willing to use this experience to help other patients facing similar situations (Vigneault et al. 2015). This model, which was notably developed in the area of mental health in the context of peer helpers (Repper and Carter 2011), can also be applied in other areas of medicine where patients have episodes of care that can have a significant impact on their everyday lives. Working in conjunction with other healthcare professionals, these accompanying patients provide both emotional and informational support related to the lived experience of the health condition encountered.

Engagement of patients and families at the organizational level can encompass all situations related to the organization of the delivery of services. This engagement can be at the strategic level, for example, in a managerial committee (Ewalds Mulliez et al. 2018), or at an operational level, such as in a continuous quality improvement team preparing for the accreditation of a health institution (CPSI 2017). In this context, patients are using their lived experience to guide and co-construct solutions to the benefit of all patients who may use these services that require development or improvement.

At a political level, we find patients and families engaged with policy makers and other experts, finding solutions for communities, helping to define public policies and establishing health priorities and resource allocation (Pomey et al. 2015a).

In Quebec, during the development of the reference framework of the partnership approach between patients, their relatives and health and social services professionals, patient partners were also integrated into work teams with the MSSS (MSSS 2018).

\section{Best Practices for Preparing Teams for Engagement and Partnership with Patients and Families}

One of the reasons that can be invoked to explain the mixed results of patient engagement in the literature (Bombard et al. 2018; Todd et al. 2000; Tritter and McCallum 2006) is the lack of rigorous preparation, on the one hand, of teams to work with patients and families and, on the other hand, of patients and families to be ready to engage. A methodology for structuring team preparation to work with patients has been set in place to optimize engagement that leads toward collaboration and co-construction. To describe this method, we take the example of Quebec's Partnership in Care Program (PCP) (Pomey et al. 2015c). This program launched in 2011 and enabled 26 teams from different institutions or organizations (hospitals, family medicine groups and long-term care residences) to set up continuous quality improvement committees (CICs) including patient and family partners. These CICs had wide-ranging mandates and reached areas as diverse as logistics, space planning, administrative decision-making, including clinical organization, and the relational and educational aspects of care.

\section{Raising awareness among directors and managers is essential for the smooth implementation of teamwork with patients ...}

\section{Awareness}

When teams are mandated to work with patients, it is essential that at the level of governance, where the commitment to engage patients has been made, there is an adherence to the partnership approach and to the structured methods to be implemented. During implementation of the PCP, the program was presented to the executive directors of the health and social services institutions involved to ensure that they understood and adhered to an overall philosophy of partnership in care and services as well as to the importance of teamwork, including clinical managers, professionals and patient partners. Raising awareness among directors and managers is essential for the smooth implementation of teamwork with patients because when these individuals adhere to this philosophy, they are thus more inclined to allocate the necessary resources to fulfill this commitment. The PCP allowed time for the participation of professionals/personnel in the conduct of the program. Also, leaders in departments for which CICs were set up were also interviewed to ensure that they understood the partnership program and thereby allocated the resources necessary for the realization of these committees.

A communications plan should be considered from the beginning to ensure that each stage of the team's work will capture relevant information to be publicized at the right time and to the right stakeholders, including an emphasis on the positive impact of the engagement of patients. In the PCP, presentations to the entire team were made so that all team members were aware of the current process of patient engagement. Stakeholders were also made aware via communications on the organizations' websites or in local newspapers.

\section{Selection and preparation of team members}

When a team is interested in or has been chosen to work with patient partners and families, special attention must be paid to 
the team's mandate. The nature of the mandate will help determine the constitution of the team to ensure that the people chosen are the best to respond to the mandate's objectives and to determine the profile of patients who will have the necessary significant experience of care and services.

In many institutions in Quebec, personnel of quality improvement departments are identified to support the development of patient partnership. These individuals can help with the selection and preparation of patient partners. For example, recruitment begins with the identification of potential patient partners via clinicians, patient associations or calls via social media. The patients are then selected, if possible, by a duo made up of a patient recruiter and a qualified manager or staff person in charge of partnership. The patient recruiter is often a patient who has had previous experience working in partnership with professionals, managers or healthcare leaders. The recruitment of the patient partner is made by this duo through a telephone or face-to-face (in-person) interview based on predetermined criteria (see the example in Box 1). In all cases, it is important to recruit patient partners who want to get involved as well as teams of professionals motivated to transform their practices.

BOX 1.

Patient selection criteria

- Expresses him/herself clearly and simply

- Expresses general health network concerns through a constructive attitude in his/her interventions

- Has significant life experience with the disease

- Has significant experience in healthcare and services targeted by the project

- Is in a steady state of health at the time of recruitment (not in an acute or crisis situation)

- Has the ability to share his/her own experience with the disease and has learned to live with it

- Can generalize his/her own experience to other contexts of care

- Demonstrates a desire to help people and contribute to an objective that goes beyond his/her individual experience

- Has interpersonal skills to facilitate collaboration (listening, empathy, etc.)

- Has a critical mind, even within teams in which he/she has already been a patient

- Understands the vision and implications of the partnership in health(care) model

- Is available and motivated to commit during the duration of the project

Source: Direction collaboration et partenariat patient 2015.

Once selected, patients and family members are given training on patient partnership in care and services and on co-construction. This training can be given either by the individual(s) in charge of patient partnership in the quality improvement departments, ideally with patient partners as co-trainers, or by CEPPP, which offers training both online and in person. Training can be done for patients and for professionals independently or simultaneously; however, training of the whole team together is preferable to begin team building and cohesion. In some circumstances, the number of patient partners recruited can be equal to the number of professional stakeholders as this can help promote co-construction.

In the PCP, the creation of the $\mathrm{CIC}$ made it possible to establish the number of people, between six and eight, necessary to constitute these teams. The composition of the team took into consideration representation of the different professionals of each program. These professionals were motivated to participate, were recognized as leaders by their peers and had sufficient time to attend meetings and complete work between these meetings. Patients were recruited in sets of two for each committee so that they would not feel isolated and to ensure the presence of at least one patient partner in case the other was not able to participate. Recruitment and training were done at the same time for all CIC members, supported by external expert patient recruiters.

\section{Realization of the mandate}

One of the optimal factors for teams to achieve a mandate that meets SMART (Specific, Measurable, Attainable, Relevant and Timely) objectives is the presence of two key players. The first is an individual who coaches professionals and managers, and the other is an individual who coaches patients and families. The person who coaches patients and family members is a patient coach who has experience working in partnership with professionals and managers. These coaches help ensure that all team members understand what is expected of them; they are also responsible for the smooth running of work sessions (Baker et al. 2016; CPSI 2017; CPASS 2014; Pomey et al. 2015c), including ensuring that the teams have structured agendas, along with accessible documents with adequate levels of literacy (CPASS 2014; Pomey et al. 2015c). This support helps prevent patients from being used in a tokenistic way. Another important element in achieving the mandate is to favour shared leadership between a patient and a healthcare professional. Indeed, the facilitation of a working group by a patient-professional duo makes it possible to balance powers and to ensure that the point of view of patients is taken into consideration at the same level of importance as that of the care provider. During the mandate, testimonials from patient partners at different levels of the organization can also help support the implementation of the patient partnership model with other internal stakeholders.

In the case of the PCP, health organizations identified individuals, called institutional collaborative leaders (ICLs), to stimulate and support collaboration among patients, managers and clinicians. In complement, patient coaches supported and accompanied other patient partners to ensure that these 
patients could express themselves freely and respectfully. In case of problems, patient coaches also played the role of mediator with other members of the team in collaboration with the ICL to find solutions. The CIC teams were facilitated by a team manager; however, it would have been interesting to go as far as to co-animate with one of the two patient partners. Patient partners who participated in the CIC were not paid but were able to receive compensation for costs incurred to participate in these activities. Information on the status of the CIC's progress was regularly presented to upper management committee(s) of the institutions.

The presence of patients in committees also raises the question of remuneration or compensation. Current MSSS regulations prohibit remuneration of patients by public healthcare institutions (MSSS 2018). However, it is possible to consider these patients as volunteers and, as such, to compensate them for the costs incurred by their engagement (e.g., transportation, parking, meals).

\section{The selection of managers to carry out the approach within the organization is crucial and must be strategic ...}

\section{Assessing patient engagement}

One point that is too often neglected is the importance of assessing the contribution of patient partners and professionals as well as their experience of the work conducted together (Pomey et al. 2017). Indeed, throughout the life cycle of a mandate for teams including patient partners, it is important to evaluate (i.e., via questionnaires or interviews) not only the progress of the work but also the perception of team members. These assessments, whatever the form, should allow stakeholders to reflect on what they did or did not like and to suggest ways to improve. Increasingly, new questionnaires are being developed to make this type of assessment possible (Phillips et al. 2015). Another important activity is to ensure that all members of the team are recognized for their commitment and are made aware of the impact they have had on the future and continuation of each mandate. This can be done through written acknowledgements (i.e., letters, e-mails, recognition on reports, etc.), oral communications (telephone calls) and acknowledgement at the organizational level (e.g., internal and external publications).

Halfway through the mandate of the CIC, an autoreflexive exercise within the teams helped adjust the mechanisms of co-construction and optimize the partnership between care providers, managers and patient partners. At the end of the CIC, both patient partners and the professionals completed a questionnaire on their experience that revealed great satisfaction from both groups on the process of co-construction and of the achievement of the objectives pursued. Interviews with managers at various levels of governance of the institution(s) and members of the CIC highlighted the factors that facilitated the implementation of patient partnership within each institution. CIC products (e.g., clinical pathway algorithms, educational tools, websites, questionnaire results and surveys) were disseminated within and across institutions. The contribution of all members was systematically recognized by certificates or recognition events, supported by the communications plans implemented by each institution.

\section{Conclusion}

The engagement of patient partners in teams needs to be structured not only for the patients involved but also for all stakeholders in these teams. A formal methodology to prepare and structure teamwork with patients has been implemented in Quebec to optimize engagement that leads toward collaboration and co-construction in partnership. This methodology is composed of four steps: (1) awareness, (2) selection and preparation of team members, (3) realization of the mandate and (4) assessment of patient engagement. Raising awareness requires a strong management team with the courage and audacity to transform an institution by embracing the patient partnership model. Partnership should be seen as everyone's business, from the $\mathrm{CEO}$ to orderlies. The selection of managers to carry out the approach within the organization is crucial and must be strategic as these individuals will champion and embody this partnership model. The second step requires the establishment of a structure allowing for the identification, recruitment, training and coaching of patient partners and their professional counterparts either at a central function or at the level of each program. It can be helpful to ask for support from external expert organizations to enhance this process. Moreover, a communications plan must be in place to mobilize regular patient testimonials at key moments during implementation of the patient partnership model. As the mandate progresses, patients, families and caregivers must be supported throughout the engagement process to help free them from concerns in what can sometimes be uncharted territory for all stakeholders. Team members will learn in action through a reflexive approach led by an experienced professional or a professional/patient partner tandem. To optimize engagement, it is important to evaluate the teamwork throughout to ensure that patients are never used as tokens and that their participation is well recognized through an assessment of their contribution. Finally, the will and perseverance of committed leaders; appropriate preparation of management, teams, patients and families; support for sustained engagement; and stimulating and charismatic efforts from both patient and professional champions will eventually pave the way toward a more humanized healthcare system. $\mathrm{HQ}$ 


\section{Acknowledgements}

The co-authors thank Mohamed Abdelhay and Émad Helmy for the translation, and Yannick Gayama and Caroline Wong for their contributions in editing, which helped bring greater clarity and focus to the article.

\section{References}

Accreditation Canada (Agrément Canada). 2015. Les soins centrés sur l'usager et la famille-Quality Matters - Qmentum pour une meilleure santé. Retrieved April 10, 2018. <https:// accreditation.ca/guide/>.

Agency for Healthcare Research and Quality (AHRQ). 2013. Readiness to Partner with Patient and Family Advisors. Retrieved April 10, 2018. <https://www.ahrq.gov/sites/default/files/wysiwyg/ professionals/systems/hospital/engagingfamilies/strategy $1 /$ Strat 1 Tool_14_HO_508.pdf>.

Armstrong, N., G. Herbert, E.L. Aveling, M. Dixon-Woods and G. Martin. 2013. "Optimizing Patient Involvement in Quality Improvement." Health Expectations 16(3): e36-e47.

Baker, G.R., M. Judd and C. Maika, eds. 2016. Patient Engagement: Catalyzing Improvement and Innovation in Healthcare. Toronto, ON: Longwoods Publishing Corporation.

Batalden, M., P. Batalden, P. Margolis, M. Seid, G. Armstrong, L. Opipari-Arrigan et al. 2016. "Coproduction of Healthcare Service." BMJ Quality \& Safety 25(7): 509-17.

Bombard, Y., G.R. Baker, E. Orlando, C. Fancott, P. Bhatia, S. Casalino et al. 2018. "Engaging Patients to Improve Quality Care: A Systematic Review." Implementation Science 13: 98. doi:10.1186/s13012-0180784-z.

Canadian Patient Safety Institute (CPSI). 2017. Engaging Patients in Patient Safety - A Canadian Guide. Retrieved April 15, 2018. <http:// www.patientsafetyinstitute.ca/EngagingPatients>.

Carman, K.L., P. Dardess, M. Maurer, S. Sofaer, K. Adams, C. Bechtel et al. 2013. "Patient and Family Engagement: A Framework for Understanding the Elements and Developing Interventions and Policies." Health Affairs 32(2): 223-31.

Centre of Excellence on Partnership with Patients and the Public (CEPPP). 2018. "Who We Are." Retrieved April 10, 2018. <https:// ceppp.ca/en/about-us/>.

Coulter, A. 2012. "Patient Engagement-What Works?" Journal of Ambulatory Care Management 35(2): 80-89.

Coulter, A. and J. Ellins. 2007. "Effectiveness of Strategies for Informing, Educating, and Involving Patients." BMJ 335(7609): 24-27.

CPASS. 2014. Programme partenaires de soins: rapport d'étape (20112013) et perspectives. Montréal, QC: Université de Montréal, Direction collaboration et partenariat patient.

Cunningham, R. and M.K. Walton. 2016. "Partnering with Patients to Improve Care: The Value of Patient and Family Advisory Councils." Journal of Nursing Administration 46(11): 549-51.

Direction collaboration et partenariat patient. 2015. Recrutement des patients partenaires. Retrieved April 10, 2018. <http://docplayer. fr/71714641-Recrutement-des-guide-pratique-patients-partenairesdocument-produit-par-l-equipe-de-la-direction-collaboration-etpartenariat-patient-dcpp.html>.

Ewalds Mulliez, A.P., M.P. Pomey, J. Bordeleau, F. Desbiens and J.F. Pelletier. 2018. "A Voice for the Patients: Patient Engagement in Mental Health through the Implementation of a Strategic Organizational Committee." Submitted for publication.
Grande, S.W., M.J. Faber, M.A. Durand, R. Thompson and G. Elwyn. 2014. "A Classification Model of Patient Engagement Methods and Assessment of Their Feasibility in Real-World Settings." Patient Education and Counselling 95(2): 281-87.

Groene, O., R. Sunol, N.S. Klazinga, A. Wang, M. Dersarkissian, C.A. Thompson et al. 2014. "Involvement of Patients or Their Representatives in Quality Management Functions in EU Hospitals: Implementation and Impact on Patient-Centred Care Strategies." International Journal of Quality Health Care 26 Suppl 1: 81-91.

Institute for Healthcare Improvement (IHI). 2014. Safety Is Personal: Partnering with Patients and Families for the Safest Care. Retrieved August 27, 2018. <http://www.ihi.org/resources/Pages/Publications/Safety-IsPersonal-Partnering-with-Patients-and-Families-for-the-Safest-Care.asp $\mathrm{x}>$. Jouet, E., O. Las Vergnas and L. Flora. 2012. "Priznavanje izkustvenega znanja bolnikov in bolnic-pregled stanja" (in Slovak, translation: "Patients' Experiential Knowledge Recognition - A State of the Art"). Socialno Delo 51(1-3): 87-99.

Ministère de la santé et des services sociaux du Québec (MSSS). 2015. Programme national de santé publique 2015-2025. Québec: Gouvernement du Québec. Retrieved April 10, 2018. <http://publications.msss.gouv. qc.ca/msss/document-001565/>.

Ministère de la santé et des services sociaux du Québec (MSSS). 2018. Cadre de référence de l'approche partenariat entre les usagers, leurs proches et les acteurs en santé et services sociaux. Québec: Gouvernement du Québec. Retrieved April 10, 2018. <http://publications.msss.gouv. qc.ca/msss/document-002061>.

Phillips, N.M., M. Street and E. Haesler. 2015. "A Systematic Review of Reliable and Valid Tools for the Measurement of Patient Participation in Healthcare." BMJ Quality \& Safety 25: 110-17.

Pomey, M.-P., L. Flora, P. Karazivan, V. Dumez, P. Lebel, M.-C. Vanier, et al. 2015a. "Le Montreal Model : enjeux du partenariat relationnel entre patients et professionnels de la santé." Santé Publique HS (S1): 41-50.

Pomey, M.-P., D.P. Ghadiri, P. Karazivan, N. Fernandez and N. Clavel. 2015b. "Patients as Partners: A Qualitative Study of Patients' Engagement in Their Health Care." PLoS ONE 10(4): e0122499. doi:10.1371/journal.pone.0122499.

Pomey, M.-P., H. Hihat, M. Khalifa, P. Lebel, A. Néron and V. Dumez. 2015c. "Patient Partnership in Quality Improvement of Healthcare Services: Patients' Inputs and Challenges Faced.” Patient Experience Journal 2(1): 29-42.

Pomey, M.-P. and P. Lebel. 2016. "Patient Engagement: The Quebec Path." Healthcare Papers 16(2): 78-83.

Pomey, M.-P., É. Morin, C. Neault, N. Clavel, M. Beaumont and M. D'Amour. 2017. "Engager les patients à tous les niveaux de gouvernance : l'exemple du CIUSSS de la Mauricie-et-du-centre-du Québec." Le point en santé et services sociaux 12(4): 12-17.

Repper, J. and T. Carter. 2011. "A Review of the Literature on Peer Support in Mental Health Services." Journal of Mental Health 20(4): 392-411.

Richards, T., V.M. Montori, F. Godlee, P. Lapsley and D. Paul. 2013. "Let the Patient Revolution Begin.” BMJ346: f2614. doi:10.1136/bmj.f2614. Todd, S., D. Felce, S. Beyer, J. Shearn, J. Perry and M. Kilsby. 2000. "Strategic Planning and Progress under the All Wales Strategy: Reflecting the Perceptions of Stakeholders." Journal of Intellectual Disability Research 44(Pt 1): 31-44. doi:10.1046/j.1365-2788.2000.00248.x.

Tritter, J.Q. and A. McCallum. 2006. "The Snakes and Ladders of User Involvement: Moving Beyond Arnstein.” Health Policy 76(2): 156-68. Vigneault, K., J. Higgins, M.-P. Pomey, J. Arsenault, V. Lahaie, A.-M. Mercier et al. 2015. "Bringing Patient Advisors to the Bedside: A Promising Avenue for Improving Partnership between Patients and Their Care Team.” Patient Experience Journal 2(2): 16-22. 


\section{About the Authors}

Marie-Pascale Pomey is a public health physician and professor at the University of Montreal. She is also a researcher at the Centre hospitalier universitaire de Montréal (CRCHUM), research chair in Technology Assessment and Advanced Practices and co-director of the Centre of Excellence on Partnership with Patients and the Public.

Paule Lebel, MD, MSc, is a professor in the Department of Family Medicine and Emergency Medicine, Faculty of Medicine, University of Montreal.

Nathalie Clavel is a PhD candidate in public health, University of Montreal, School of Public Health and Research Centre of the University of Montreal Health Centre. Her thesis focuses on the practices of healthcare organization managers in the implementation of patient engagement in quality improvement and direct care.

Édith Morin is a patient and manager at the Integrated University Health and Social Services Centres (CIUSSS), Mauricie-Centre-duQuébec.
Mireille Morin is a patient partner at the University of Montreal Hospital Centre (CHUM), Montreal.

Catherine Neault is the manager of quality, accreditation and user experience and senior advisor at the Integrated University Health and Social Services Centres (CIUSSS), Mauricie-Centre-duQuébec.

Benoît Tétreault, MPH, MSc (Speech Language Pathology), is associate director of the Multidisciplinary Services Directorate of the Integrated Health and Social Services Centre (CISSS) of Laval. Over the past few years, he has also led the implementation and deployment of the Care and Services Partnership within the CISSS de Laval.

Anna-Paulina Ewalds Mulliez, MSc, holds a masters degree in health services administration, University of Montreal, School of Public Health. Her master's thesis examined the implementation of patient engagement in mental health. 